CASE REPORTS

\title{
Hereditary nephritis (with unusual renal histology): report of a first case from the West Indies
}

\author{
J. S. HAYES \\ M.B., M.R.C.P.
}

\author{
N. JANKEY \\ M.D., M.R.C.Path.
}

General Hospital, Port-of-Spain, Trinidad, West Indies

\begin{abstract}
Summary
A 21-year-old Grenadian girl undergoing investigation in Trinidad for anaemia was diagnosed as a case of hereditary nephritis. She had the clinical features of a nephropathy, nerve deafness and an ocular defect. Renal histology was exceptional in that in addition to the typical findings of a hereditary nephritis, cystic areas generally associated with medullary cystic disease were noted. Several members of the patient's maternal family were afflicted with either deafness, visual disturbances or renal disease.
\end{abstract}

\section{Introduction}

The role of heredity and familial predisposition in the pathogenesis of nephritis was first recognized by Dickinson in 1875. Alport, in 1927, further consolidated knowledge on the subject and remarked upon deafness being a notable associated feature of the disorder. Sohar observed, 29 years later, that lens abnormalities might occur in the syndrome (Sohar, 1956).

Since 1950 several reports of hereditary nephritis have appeared in the world literature. It is thought to affect males more particularly and should be considered in any patient presenting with unexplained haematuria commencing in childhood.

This patient is of particular interest in that she is the first case of its kind to be described from the English-speaking Caribbean.

\section{Case report}

A 21-year-old Grenadian girl (E.D.) was admitted to the Port-of-Spain General Hospital for investigation of anaemia.

She gave a history of difficulty in seeing distant

Reprint requests: Dr J. S. Hayes, General Hospital, Port-of-Spain, Trinidad. objects since birth and she had had slight difficulty in hearing especially on the right side for as long as she could remember.

Her main complaints at the time of admission were weakness, pruritus and anorexia.

On examination she was very pale. There was no lymphadenopathy, and the blood pressure was $90 / 68 \mathrm{mmHg}$. There were no abnormalities in the cardiovascular, respiratory, or alimentary systemso Clinically she had nerve deafness on the right side and ophthalmological examination revealed the presence of anterior lenticonus. There was no evidence of peripheral nerve impairment.

\section{Investigations}

Blood-haemoglobin, $8.2 \mathrm{~g} / 100 \mathrm{ml}$; white cell count, $5600 / \mathrm{mm}^{3}$; platelets, $141,000 / \mathrm{mm}^{3}$; serum creatinine, $6.9 \mathrm{mg} / 100 \mathrm{ml}$; blood urea, $204 \mathrm{mg} / 100$ $\mathrm{ml}$. Electrolytes-sodium, $140 \mathrm{mEq} / \mathrm{l}$; potassium, $5.2 \mathrm{mEq} / \mathrm{l}$; chlorides, $111 \mathrm{mEq} / \mathrm{l} ; \mathrm{CO}_{2}, 13 \mathrm{mEq} / \mathrm{l}$; serum cholesterol, $220 \mathrm{mg} / 100 \mathrm{ml}$; serum comple ment, $130 \mathrm{mg} / 100 \mathrm{ml}$; uric acid, $6.4 \mathrm{mg} / 100 \mathrm{ml}$ Protein, $1.5 \mathrm{~g}$, and $141 \mathrm{mEq}$ of sodium, respectively, were excreted in the urine per $24 \mathrm{hr}$. Urinalysis$60 \mathrm{WBC}$ per high power field, several white cell casts per low power field. Urine culture-Streptococcus faecalis sensitive to ampicillin, carbenicillin and doxycycline. Serum calcium, $10.4 \mathrm{mg} / 100 \mathrm{ml}$. Phosphorus, $7.0 \mathrm{mg} / 100 \mathrm{ml}$; alkaline phosphatase, $10 \mathrm{KAu}$.

Radiology -erect film of the abdomen; bilaterally small kidneys. Open renal biopsy (Fig. 1a): wedge biopsy $1.5 \mathrm{~cm}$ wide $\times 0.5 \mathrm{~cm}$ deep; gross-small cysts at the corticomedullary junction, the largest being $3 \mathrm{~mm}$ in diameter; microscopy-periglomerular fibrosis and mesangial proliferation in some glomeruli, almost total fibrosis in other glomeruli. The tubules were dilated. There was interstitial 
fibrosis, and chronic inflammatory infiltrate. Staining with oil, Red-O and Sudan IV showed scattered lipid-laden macrophages. The arteries were normal. Figure 1 shows two cysts; one immediately adjacent to the glomerulus undergoing fibrosis in the upper right hand corner, the other lying at 7 o'clock to that glomerulus. Figure 1b is an enlarged photograph of the cyst adjacent to the partially fibrosed glomerulus. The cysts were lined with flattened epithelium.

Audiometry (Fig. 2) - bilateral impairment of hearing of a nerve deafness type.

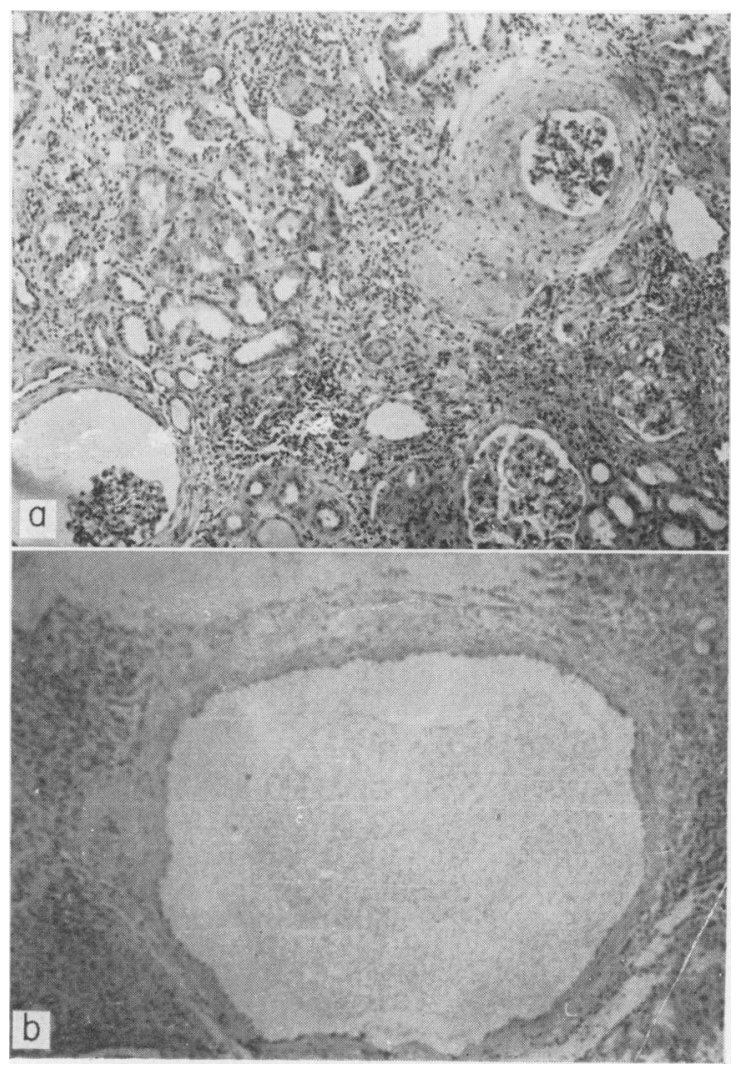

FIG. 1. (a) Microscopic appearance of renal biopsy showing two cystic spaces in close relationship to the partially fibrosed glomerulus in the upper right hand corner. Three foam cells are noted lying between the cysts. (b) Enlarged photograph of cystic space.

\section{Family history (Fig. 3)}

The patient had one full sister who remains in perfect health. One maternal half-brother has an abnormal urine sediment with proteinuria and microscopic haematuria. In addition, he has had significant deafness from the age of 6 years, and is myopic. One maternal half-sister is healthy whilst

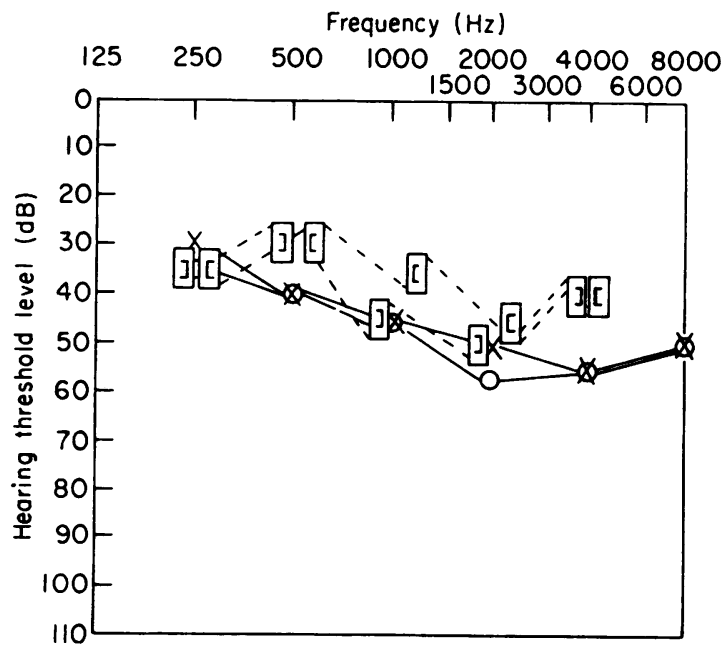

Fig. 2. Audiogram revealing bilaterally impaired hearing. Audiogram plotted on basis of American National Standard (ANSI).

another half-brother is only 18 months old. One of the mother's sisters has mildly impaired hearing. Three other sisters have worn spectacles since their teens. The maternal grandfather developed marked difficulty in seeing at the age of 45 years. The son of one of his sisters died from renal failure at the age of 24.

A diagnosis of hereditary nephritis with chronic renal failure was made. The patient was put on a $20 \mathrm{~g}$ protein diet and antibiotics prescribed for her urinary tract infection. She died, however, from endstage renal failure 9 months after first being diagnosed.

Post-mortem examination (Fig. 4a and b) showed the kidneys were grossly contracted, their surface

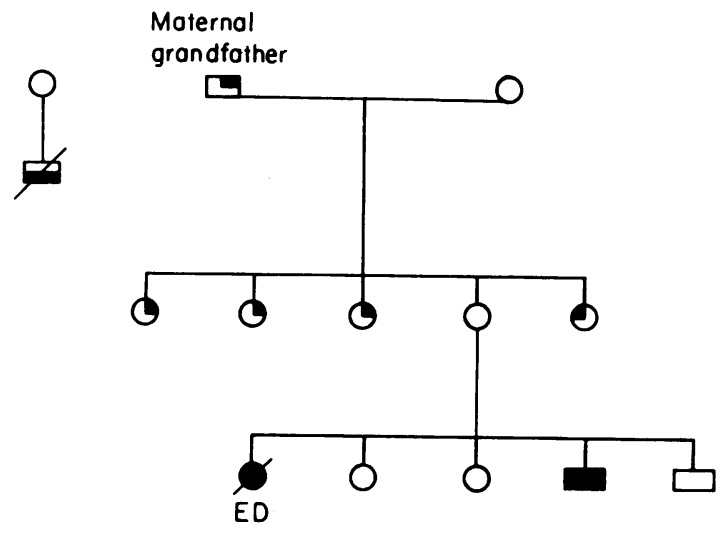

FIg. 3. Family tree. $\square$, Male; $\bigcirc$, female; $\odot$, ocular defect; $\odot$, hearing defect; $\square$, renal disease;/, deceased. 

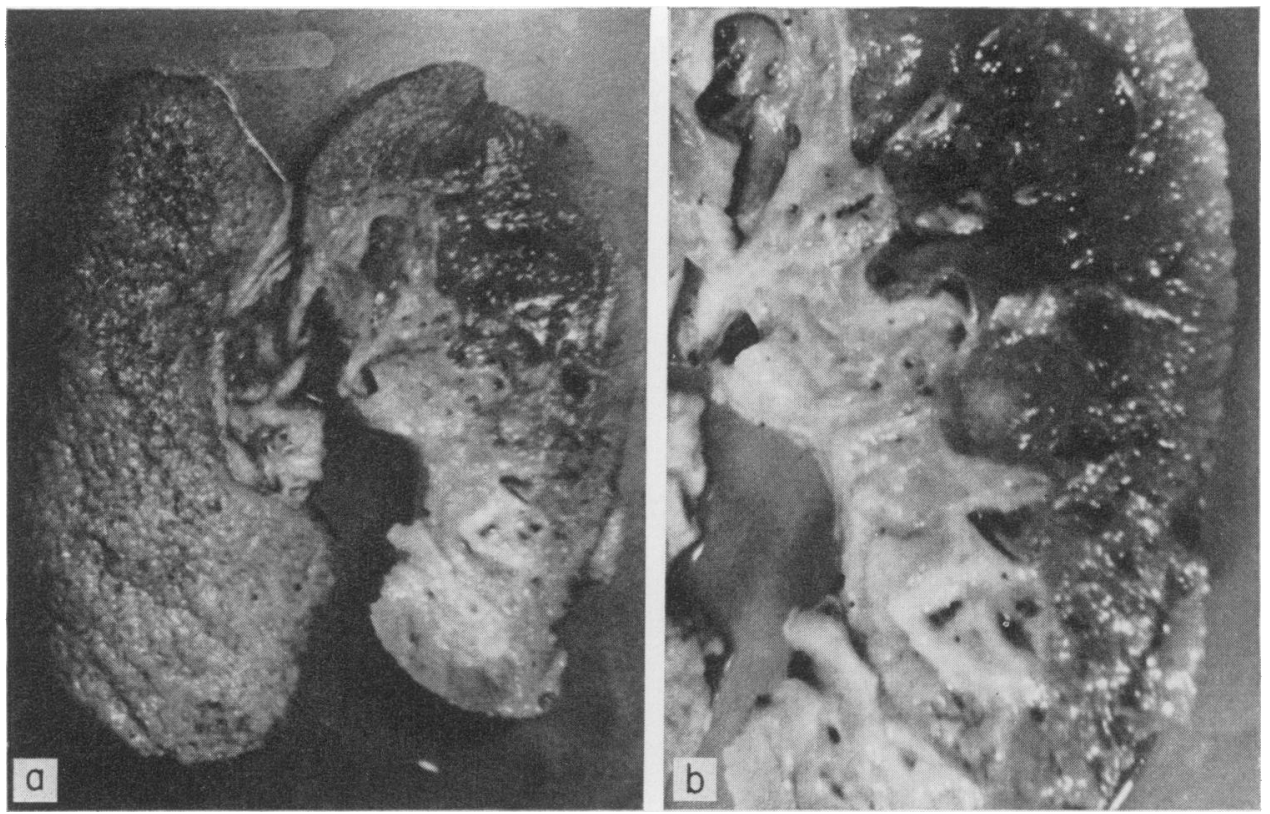

Fig. 4. (a) Post-mortem appearance of kidney, the cut surface disclosing cortico medullary cysts.

(b) Enlarged photograph of the cut surface showing the cysts to greater advantage.

granular and cortices thinned. The outstanding feature was the presence of large cysts at the corticomedullary junctions.

\section{Discussion}

The patient presented with the classical features of hereditary chronic nephritis-renal disease, nerve deafness and lens abnormalities. Histologically, the appearance of foam cells in the tubular interstitium further reinforced the diagnosis. Although foam cells might appear in other glomerular disorders, they are a regular feature of hereditary nephritis (Krickstein, Gloor and Balogh, 1966; Spear and Slusser, 1972). Typically, they are scattered throughout the renal cortex, but tend to be concentrated mainly around the cortico-medullary junction in advanced cases (Perkoff, 1967). Foam cells are thought to be lipidladen macrophages and Krickstein et al. believed them to be tubular rather than interstitial in origin.

The remainder of the renal biopsy was interesting. There were the expected findings generally associated with hereditary nephritis; the periglomerular fibrosis, glomerular proliferation, chronic inflammatory cell infiltration; but, in addition, cysts at the corticomedullary junction were noted. These were quite unlike dilated renal tubules and were lined with flattened epithelium. They resembled closely the cysts of medullary cystic disease. Fairley, Leighton and Kincaid-Smith (1963) described a family in which three of five siblings had visual defects as well as polycystic kidney disease, medullary cystig disease and medullary sponge kidney respectively $\overrightarrow{0}$ Medullary cystic disease generally leads to chronif. के renal failure; the proposed modes of inheritance are? thought to be closely similar to hereditary nephritis (Perkoff, 1967), but they are two entirely separate disease entities.

A search of the literature has failed to produce previous reports of a pathological picture of medullary cystic disease coexisting with or superimposed on one of hereditary nephritis.

The anterior lenticonus found in the patient is one of the ocular abnormalities which could be detected in the disorder, the others being congenital cataracts, congenital nystagmus, myopia and spherophakia (Perkoff, 1967). The possible aetiological basis for the eye lesions will be discussed later in this paper.

E.D. was unusual in that, although a female, she had advanced renal disease and significant deafness at an early age. It is widely believed that males are more severely affected than females, and in the latter, deafness is usually recognized only on audiometry (Alport, 1927; Perkoff et al., 1958; Chappell and Kelse, 1960). However, Kaufman et al. (1970) had three in their series of eleven females developing renal failure. There have been other reports of females contracting progressive renal disease (Chappell and Kelse, 1960), implying that they are not completely exempt from this catastrophe. 
The patient gave no history of recurrent haematuria with which such cases generally present. The finding of pyuria here was not unusual; $37 \%$ of the cases reported by Kaufman et al. had this feature as one of the presenting clinical manifestations. The remarkably normal blood pressure and proteinuria in non-nephrotic quantities are features quite typical of hereditary nephritis.

There has been much speculation as to the precise aetiology of the syndrome. It is generally accepted that alterations in the glomerular basement membrane which include focal thickening and distortion of the lamina densa are among the earliest changes noted (Rome, Cuppage and Vertes, 1966; Sessa et al., 1974; Spear and Slusser, 1972). These might be present before the onset of overt renal disease. Atrophy of the spiral ganglion at the base of the acoustic nerve was found at the post-mortem of two brothers (Dubach and Gsell, 1962). The theory has been advanced that a metabolic or enzymatic disturbance of the synthesis mechanism of the basement membranes of the glomerulus, lens capsule, and organ of Corti is responsible for the various clinical manifestations (Kaufman et al., 1970; Sessa et al., 1974). Kefalides (1972) found the basement membranes of the three organs to be very similar biochemically, in that all contain large quantities of hydroxyproline, hydroxylysine, and glycine. No conclusive evidence is forthcoming for an immunological basis for the disorder (Kaufman et al., 1970; Spear, Whitworth and Königsmark, 1970; Spear and Slusser, 1972). In this particular case, although immunofluorescent studies were not performed on the renal biopsy specimen, the serum complement was normal.

From the family data, it is very evident that the source of inheritance of the disease was through the mother with genetic transmission by the maternal grandfather. A nephew of his died from renal disease. E.D.'s maternal half-brother has an abnormal urine sediment, deafness and defective vision. The question as to the precise mode of inheritance of hereditary nephritis is not fully resolved. On the one hand, there is the suggestion that it might be by an autosomal dominant gene (Perkoff, 1964), on the other hand, other workers have put forward evidence for a sexlinked type of inheritance (Stephens et al., 1951; Rome et al., 1966).

E.D. is the first case of hereditary nephritis to be reported from the West Indies. It would be worthwhile to make a more comprehensive study of her family in order to ascertain how many members are afflicted with the full-blown disease or the different components of the syndrome.

\section{Acknowledgments}

We wish to thank Dr P. Ratan, Consultant Physician for permission to investigate this patient, $\mathrm{Mr} \mathrm{K}$. A. Butler who performed the renal biopsy, Dr L. M. Commissiong, Chief Medical Officer, Grenada, and Mrs Geraldine Perrotte, Public Health Nurse, Ministry of Health, Grenada, for assistance in locating the patient's relatives, and Glaxo, Allen and Hanbury's for a research grant for this project.

\section{References}

AlPORT, A.C. (1972) Hereditary familial congenital haemorrhagic nephritis. British Medical Journal, 1, 504.

Chappell, J.A. \& Kelse, W.M. (1960) Hereditary nephritis. American Journal of Diseases of Children, 99, 401.

Dickinson, W.N. (1875) Diseases of the Kidney, I. p. 379.

Dubach, U.C. \& Gsell, O. (1962) Alports' syndrome. Lancet, i, 159.

Fairley, K.F., Leighton, P.W. \& Kincaid-Smith, P. (1963) Familial visual defects associated with polycystic kidney and medullary sponge kidney. British Medical Journal, 1, 1060.

Kaufman, D.B., Mclntosh, R.M., Smith, F.G., JR \& VERNIER, R.L. (1970) Diffuse familial nephropathy. A clinicopathological study. Journal of Pediatrics, 77, 37.

Kefalides, A. (1972) Etudes biochimiques sur les membranes basales du rein normal. Actualités néphrologiques de l'Hopital Necker, 7.

Krickstein, H.I., Gloor, F.S. \& Balogk, K. (1966) Renal pathology in hereditary nephritis with nerve deafness. Archives of Pathology, 82, 506.

Perkoff, G.T. (1967) The hereditary renal diseases. New England Journal of Medicine, 27, 79

Perkoff, G.T. (1964) Familial aspects of diffuse renal diseases. Annual Review of Medicine, 15, 115.

Perkoff, G.T., Nugent, C.A., JR, Dolowitz, D.A., Stephens, F.E., Carnes, W.H. \& Tyler, F.H. (1958) A follow up study of hereditary chronic nephritis. Archives of Internal Medicine, 102, 733.

Rome, L., Cuppage, F.E. \& Vertes, V. (1966) Familial hematuric nephritis. Pediatrics, 38, 808.

Sessa, A., Cioffi, A., Conte, F. \& D'Amico, G. (1974) Hereditary nephropathy with nerve deafness (Alport's syndrome). Electron microscopic studies on the renal glomerulus. Nephron, 13, 404.

SoHAR, E. (1956) Renal disease, inner ear deafness and ocular changes. New heredo-familial syndrome. Archives of Internal Medicine, 97, 627.

SPEAR, G.S. \& Slusser, R.J. (1972) Alport's syndrome: Emphasizing electron microscopic studies of the glomerulus. American Journal of Pathology, 69, 213.

SPEAR, G.S., WhitWORTH, J.M. \& KöNIGSMARK, B.W. (1970) Hereditary nephritis with nerve deafness. Immunofluorescent studies on the kidney, with a consideration of discordant immunoglobulins-complement immunofluorescent reactions. American Journal of Medicine, 49, 52.

Stephens, F.E., Perkoff, G.T., Dolowitz, D.A. \& Tyler, F.H. (1951) Partially sex-linked dominant inheritance of interstitial pyelonephritis. American Journal of Human Genetics, 3, 303. 